\title{
Crimes de perigo abstrato
}

\author{
Marco Aurélio Costa Moreira de Oliveira*
}

Para os ideólogos alinhados a um direito penal marcadamente repressor, prioritariamente favorável ao fortalecimento do Estado, interessa politicamente, entre outras soluções fortes, a punição dos denominados "delitos de perigo abstrato". A mera conduta, mesmo sem causar dano ou perigo de dano, passa a ser incriminada, graças a um temor generalizado de uma sociedade insegura, em decorrência das verdadeiras causas criminógenas e da crise de anomia que torna frágil a ordem jurídica.

A criação de tipos de crimes de perigo abstrato, como querem os vinculados a um pensamento voltado principalmente para a repressão, dependerá, não de uma conduta efetivamente perigosa para a vida social, ante probabilidade concreta de dano, mas de um comportamento simplesmente contrário a uma lei formal. O que interessa ao direito penal máximo é estabelecer que o crime decorra de uma previsão conceitual, para tornar poderoso e dominador 0 estado, transformando-o em uma finalidade em si mesmo. É, no entanto, esse excesso legislativo de tendência puramente repressória que, esquecendo as verdadeiras causas das condutas criminosas, deprecia a ordem jurídica e a torna frágil e pouco confiável.

Voltando às épocas remotas do direito, constatamos em contraposição à tendência expansionista de "criar" crimes formais e desnecessários, que a sociedade só entendia legítimo o interesse punitivo a ser exercido contra alguém, se se constatasse a existência

\footnotetext{
- Professor de Direito Penal e de Direito Processual Penal na Faculdade de Direito da UFRGS. Desembargador aposentado do Tribunal de Justiça do RS.
} 
de resultados materialmente danosos causados por uma conduta. Mesmo na atual fase do direito repressivo, ao se realizar o exame dos elementos do crime, sempre se parte da constatação de uma lesão a bem jurídico fundamental, para que a ordem jurídica se mobilize para punir, também, as condutas causadoras de efetivo perigo de dano.

De outra parte, o surgimento da teoria da imputação objetiva, inspirada no conceito de risco socialmente admissível, ser como fator de depuração da própria relação causal, impondo que se parta da constatação do resultado danoso para vinculá-lo à conduta de alguém. Só após, caso reconhecida a inexistência de risco admitido pela sociedade, se prosseguirá no exame de tipicidade, antijuridicidade e culpabilidade como elementos necessários à caracterização do crime e de sua punibilidade.

Modernamente, com o aumento da complexidade social e também pela necessidade de ser punido o autor de crimes tentados, mesmo sem ocorrência de resultados danosos, é que se passou a considerar delito a conduta causadora de perigo para determinado bem fundamental.

Assim, um crime sem resultado naturalístico, como o é uma tentativa branca de homicídio, deve apresentar verdadeira proximidade entre a conduta e o resultado pretendido. O perigo de dano, portanto, somente pode ser entendido como algo concreto, decorrente de uma conduta tal que coloque em real probabilidade de perecimento o bem jurídico protegido pela norma incriminadora. Ou seja, um dano que está por acontecer ou na iminência de acontecer. Diferentes, são as tentativas improfícuas em que não se vislumbra possibilidade de causação de dano.

Ou seja, sem perigo concreto para o bem protegido pelo tipo legal de crime, considera-se inexistente o próprio ato executório, elemento indispensável para a configuração de tentativa. Em consequiência, devem ser desprezados os atos meramente preparatórios por destituídos de perigo de perecimento para o bem protegido.

Os bons doutrinadores estabelecem, com segurança, que a execução de um crime se caracteriza por colocar o bem jurídico em efetivo perigo de perecimento, na linha sabidamente seguida desde Betiol (cabendo ao juiz ver se in concreto $o$ ato executado poderia ter eficácia causal em relação ao evento tido em mira - Direito Penal, ed. RT, 1971 - p. 229), e de Manzini, ambos na Itália. Da mesma forma, Maurach, na Alemanha - Tratado de Derecho Penal - II - ed. Ariel, Barcelona, 1962 - p. 176), Carrara e Vannini, citados por Hungria, no Brasil (Comentários - vol. I, tomo II, ed. Forense 58, p. 83 e 84) e Mayer (Obra citada: "atos que atacam o bem jurídico").

Sem ocorrência desse ataque ou perigo, não se deve cogitar de punição penal. Por isso, o perigo a que se submete um bem protegido por norma 
incriminadora, somente pode ser entendido como algo individualizado, pondo esse bem em concreta situação de perecimento.

Para o juiz titular de jurisdição criminal, orientado por uma concepção moderna e democrática, mesmo fazendo parte do poder estatal, mas desvinculado das inspirações dos leviatãs, a mais importante preocupação, ao lançar a sentença, é cuidar se da conduta do agente resultou alguma lesão ou, pelo menos, um efetivo perigo de perecimento de bem jurídico alheio.

Ante a sofisticação da vida social, como o são as atividades econômicas, e a intervenção do estado na vida das pessoas, passou-se também a considerar como resultados penalmente puníveis os comportamentos que podiam simplesmente causar perigos, mesmo sem possíveis alterações do mundo dos fatos. Aos poucos, na ânsia de se aumentar a proteção social, mesmo ofendendo o sistema do direito penal, começou-se a entender que ações, até mesmo ligadas remotamente a resultados prováveis ou apenas possíveis, segundo um juízo hipotético ou mesmo imaginário, deveriam ser consideradas como puníveis, desde que apresentassem potencialidade de "causar perigo". Cada vez mais, passou a acentuar-se uma ideologia punitiva, ampliando o campo das condutas penalmente condenáveis, mesmo sem estarem ligadas a um resultado danoso, ou sem apresentarem uma direta situação de dano próximo, concreto, perceptível.
A adoção de um critério, ligado ao aumento da incidência do direito penal, fez com que o crime de perigo abstrato nascesse da ideologia de endurecimento do direito penal. Essa tendência acentuou-se, cada vez mais, diante da crise de anomia a desordenar a vida da sociedade moderna pelo descumprimento das normas do universo jurídico como um todo. Constatadas debilidades e falhas da ordem estabelecida pela Constituição e pelas leis, passou-se a apelar para ameaças de punição, criando uma prevenção geral indiscriminada numa extensão abusiva e desnecessária do direito penal. Isto é, o verdadeiro direito criminal saiu de seu leito histórico, aumentando a descrença em sua efetividade.

A pretendida ampliação do penal, hoje em dia mais preocupado em punir do que em estabelecer previamente o que seja substancialmente uma conduta criminosa, apresenta-se em inegável fase de expansão legal. Em conseqüência demonstra-se responsável pela quebra de princípios essenciais à sua natureza. É inegável que as normas nascidas da nova tendência criaram um conjunto assistemático, fragmentário, amorfo e acientífico, responsável pela fragilização da segurança jurídico-penal e da quebra de sua efetividade. Afetado que está pela patologia do gigantismo, o chamado direito penal, que mais se preocupa em punir do que em definir prioritariamente a conduta punível, demonstra-se débil e destituído de respeitabilidade. 
A preconizada solução "interventiva máxima" do direito penal, atingindo várias frentes, desenvolveu-se no sentido de encontrar uma solução supletiva ou mesmo substitutiva de outros ramos do direito, entendidos como insuficientes ou inoperantes para disciplinar a vida social.

A consequiência dessa intervenção ideológica do direito penal foi a ampliação do direito punitivo, coincidente ou coextensivo com o direito civil, com o comercial, o administrativo, o tributário, o previdenciário, o trabalhista, o do consumidor e tantos outros. Chegou-se a ir além, com a superposição e anteposição do penal em relação aos demais ramos do ordenamento jurídico.

Ao mesmo tempo em que se impunham, por exemplo, sanções tributárias, com base no ramo jurídico apropriado, aplicavam-se cumulativa e desnecessariamente soluções penais. A tendência intervencionista foi mais além. Mesmo que o direito especial não incidisse sobre o fato, em decorrência de soluções administrativas, ainda assim passou-se a entender aplicável, concomitantemente, até mesmo prioritariamente, o penal, diante da denominada "independência das esferas". Pouco importa, como querem, que o ramo jurídico de natureza verdadeiramente constitutiva e não meramente sancionatória proporcione solução diversa da incidência penal. Em conseqüência, o direito penal, que somente deveria atuar quando já tivessem falhado os demais ramos, passou a ser deles independente, pouco importando que colidisse com o direito prioritário. Passou-se a condenar penalmente, antes que o direito administrativo, o tributário ou o financeiro pudessem apreciar a matéria identicamente fáctica à tratada em processo criminal.

O direito penal passou a ser o grande e poderoso guardião a tutelar a ordem jurídica em geral, atuando não somente com independência quanto aos outros ramos, como até mesmo antes e acima deles, ou com eles colidindo frontalmente e criando-se verdadeira desarmonia interna no ordenamento jurídico. Inverteu-se a destinação normal dos ramos componentes do direito. E, o que é ainda mais grave, passou-se simplesmente a desprezar o ramo materno e seus conceitos.

Diante de condutas que representem um perigo puramente abstrato, longínquo, de uma potencialidade imprecisa, passou-se a entender como aplicável o direito penal, no sentido de impedir desobediência a outros tipos de normas jurídicas. Outorgou-se ao juiz criminal uma espécie de poder de tutela geral sobre ações normalmente reguladas por outros ramos do direito. Chegou-se mais longe, ainda. Passouse a punir não somente condutas contra normas de outros ramos do direito como até mesmo simples desobediências a essas normas.

A demasia, demonstrada gritante, decorre da ideologia do crescimento penal, nascida da fragilidade e até mesmo da ineficácia das normas 
extrapenais. Em conseqüência, passouse a oportunizar ao juiz, mesmo sem se visualizar a proximidade de um dano, a atribuição de procurar potencialidades danosas e ao legislador, a competência para criar bases normativas destinadas a punir crimes de perigo. Nasceram, então, previsões genéricas, concedendo-se ao julgador um amplo espectro decisório, sem previsão específica. $\mathrm{O}$ resultado mais evidente foi o de criar normas penais em manifesta desarmonia com a regra matriz e historicamente consagrada dos crimes de perigo, contida no artigo 132 do Código Penal.

Ora, o delito do art. 132 é, sem dúvida, o grande paradigma dos demais crimes de perigo, ao exigir que a conduta crie um "perigo direto e iminente", como consta do tipo legal. Para ele não basta que se pense numa possibilidade de ocorrência de um dano futuro, potencial; é imprescindível que a conduta se avizinhe concretamente de uma lesão. (Como exemplo da tendência expansionista, pode-se citar comportamentos apenas aparentemente perigosos para o sistema financeiro. Mesmo que não se tenha emitido nenhum título de crédito que viesse a ser protestado ou executado, determinadas condutas poderiam "abalar", potencialmente, futuramente, e até imaginativamente, a seriedade das instituições bancárias e financeiras. Nesse caso não se há de falar em perigo concreto, sendo descabida a condenação de um agente que tenha apenas desobedecido a normas abstratas, sem que essa desobediência tivesse qualquer efetividade para pôr em perigo o bem jurídico protegido).

Diferentemente e longinquamente da linha tradicional, surgiram normas punitivas de perigo abstrato, dispondo de modo diverso do que historicamente se estabelecera a partir do referido crime de perigo para a vida e saúde de outrem, como consta de seu nomen júris no Código Penal e de sua restritiva redação (perigo direto e iminente).

Nasceram dispositivos penais que se valem da expressão "dano potencial", sem exigir que o perigo seja real, iminente ou direto. Com essa imprecisa "previsão" legal, poderá o juiz realizar a atividade interpretativa, avançando, até mesmo ampliativamente, in malam partem, e tornando frágil o princípio da legalidade, legalidade essa que parte sempre e necessariamente da objetividade jurídica do tipo.

Ora, os crimes de perigo abstrato não apresentam objetividade jurídica em si mesmos, salvo se se quiser entender como tal a pura desobediência a uma norma jurídica, sem lesão ou sem ameaça a direito. Com isso, o poder de decidir sobre o que seja potencialidade danosa acaba situado no âmbito do arbítrio.

A ampliação do direito penal, no sentido de punir danos abstratos (pedese perdão pela colisão semântica do termo dano com o termo abstrato), foi um dos caminhos seguidos por essa tendência de juristas, não afeitos, em sua expressiva maioria, ao direito penal sistemático e metodologicamente científico. 
Não se poderá dizer que essa linha de pensamento tenha qualidade mínima para se filiar a uma base filosófica. Ao contrário, por criar normas assistemáticas e fragmentárias, sem se endereçarem à preservação de bens fundamentais, verdadeiro objetivo do direito criminal, agride o mais singelo pensamento de cunho filosóficovalorativo. Seu desprezo à própria substância do direito criminal e à sua axiologia mostra sua inaceitabilidade. A admissão e até mesmo o incentivo a essa colidência com um universo jurídico, necessariamente harmônico dentro de si mesmo, demonstra a quebra de seu verdadeiro objeto.

A abusiva expansão do penal nasceu da grande preocupação com a falta de efetividade prática das normas extrapenais. Por isso, passou-se a procurar, em favor destas, uma bengala jurídica: o direito penal. A solução encontrada foi apelar, de modo simplista, para as sanções penais, em desarmonia com a conceituação verdadeiramente substancial de condutas previamente sacramentadas no preceito da norma como crimes.

O juridicamente aceitável, diante de tudo que se expôs, é que esse ramo do direito deva voltar a se denominar direito criminal e não penal. E que se preocupe com condutas substancialmente delituosas, necessariamente puníveis, e não apenas com um efeito penal meramente pragmático, de cunho político ou portador de um efeito promocional e simbólico dedicado a uma sociedade temerosa e a uma mídia sequiosa por notícias de punição.
A verdadeira posição filosófica e especificamente lógica do direito deve partir de um conceito substancial de crime, como fato causador de danos ou perigos concretos, que abalem a ordem jurídica. Somente diante disso, surge a necessidade da punição. E punição somente se impõem quando necessária. Aliás, o artigo 59 do Código Penal, verdadeiro elemento demonstrador da ideologia que marca a sistemática do Direito Penal, estabelece com clareza que a pena, destinada a reprovar o comportamento criminoso, deve ficar adstrita ao critério da necessidade. Ultrapassado esse critério, está-se a ofender a própria ordem penal em sua inteireza, pois a intervenção estatal não pode ser indiscriminada e arbitrária. E o limite que impede a intervenção abusiva é o próprio critério de necessidade.

O legislador que descobrisse, no meio social, condutas atentatórias a bens fundamentais, para, após, formular soluções punitivas, teria um pudor maior ao cumprir a tarefa de cominar penas, se usasse prioritariamente a lógica de estabelecer e dimensionar os preceitos criminais.

Acautelando-se em uma linha racional, sopitaria a ânsia de criar indiscriminadamente normas punitivas, de inspiração política, refreando a tendência de construir um direito penal máximo.

Legisladores e doutrinadores deveriam partir, com seriedade, de um conceito substancial de crime e não de uma suposta utilidade ou simples pragmatismo terrorista da conse- 
qüência penal. $O$ verdadeiro legislador não se deve preocupar, com cominações de penas desnecessárias, em atemorizar os agentes de comportamentos simplesmente irregulares, ou atinentes a outros ramos jurídicos, mas destituídos de potencial ofensivo a bens fundamentais para a vida social.

Não se pode aceitar, por juridicamente incorreto, o aumento demasiado do número de normas punitivas, para justificar uma suposta mas inexistente necessidade de condenações penais, mormente se as condutas incriminadas não se harmonizam com um conceito material de crime.

O que se deve punir é a conduta causadora de lesão a um bem jurídico essencial ou a ameaça concreta a um direito e não simplesmente a violação de um dever puramente formal, destituído de ofensividade. O certo é que existem, em nosso ordenamento penal, determinadas normas incriminadoras a preverem penas para condutas de simples perigo abstrato, afetando-se, assim, o conceito substancial de crime. Pune-se uma conduta como resposta a um suposto crime formal ou um crime presumido, quando se sabe que toda presunção punitiva em direito criminal demonstra-se odiosa.

Sem lesão ou perigo concreto de se atingir bens fundamentais, não se há de falar em crime, muito menos em aplicação de penas, solução que sempre dependerá do juízo prévio, incriminador de condutas delituosas. O princípio da razoabilidade resulta desobedecido sempre que se aplique pena a uma conduta que sequer represente ameaça a direito, ou que não se apresente como ontologi-camente delituosa.

Foi da tendência de expansão do direito penal (afrontando um conceito básico de crime) que surgiram as previsões de punição dos delitos de mero perigo abstrato. A incriminação dessas condutas, destituídas de perigo concreto, demonstra-se manifestamente abusiva, pois a Constituição, dispõe em seu art. $5^{\circ}$, inc. XXXV, que a lei não excluirá da apreciação do Poder Judiciário lesão ou ameaça a direito. Ou seja, juntamente com o princípio da inafastabilidade da apreciação judicial, a Carta Maior dispõe que a exigência da submissão de fatos ao exame judicial se faça relativamente a uma lesão efetiva a um bem, ou a ameaça a direito.

Ora, a ameaça a um direito decorre da conduta do agente que tenha em mira ofender um bem fundamental protegido pelo ramo do direito definidor de crimes.

Não há como deixar de concluir que a ameaça está ligada, necessariamente, a uma lesão a ser produzida, pois quem pratica a ameaça pelo menos aceita lesionar, ou intimidar, ou afetar um direito, prometendo um castigo ou malefício ao sujeito passivo. A ameaça está vinculada, sempre e necessariamente, a um dano concreto, nunca abstrato, ou nada abstrato, pois a noção de ameaça a um direito é incompatível com algo intangível ou meramente potencial. O ramo criminal não pode cuidar de exercícios hipotéticos. 
Quem ameaça um direito, pensa no perecimento de direito alheio ou do bem protegido por esse direito. Nada há de abstrato, portanto.

Pode-se até admitir, mas apenas para argumentar, que os delitos de perigo abstrato não chegam a ofender formalmente a letra da norma constitucional, presente no art. $5^{\circ}$, $\mathrm{XXXV}$, por não vedar que outras conseqüências jurídicas possam ser submetidas ao Judiciário. No entanto, não resta nenhuma dúvida de que a tipificação legal de crimes de perigo abstrato afronta a ideologia e a principiologia da Constituição. Esta somente se preocupa em assegurar obrigatória atuação judicial quando se constatarem lesões ou ameaças a direitos. Nem se pode entender de outra maneira, pois a lei maior, ao estabelecer o princípio da inafastabilidade de apreciação judicial, é clara quanto ao objeto dessa apreciação, isto é, a causação de uma lesão ou a ameaça a direito, consequiências que a lei exige, sejam submetidas ao Judiciário. E ameaça somente se pode direcionar contra algo, de modo direto e iminente.

Se alguém praticar ação definida como crime de mera conduta, sem causar nenhum perigo concreto, a solução vem representada pela aplicação de sanções administrativas ou civis, mas certamente extrapenais. Isso porque os "perigos abstratos" não podem ser punidos penalmente. De um lado, porque nenhum perigo pode ser abstrato, pois a abstração não é perigosa; de outro, por limitar-se a desobedecer a uma proibição, sem que disso resulte perigo direto e iminente para determinado bem fundamental.

Assim, há de se concluir, em conformidade com o disposto no art. $5^{\circ}, \mathrm{XXXV}$, da Constituição Federal, como já se enfatizou, que o direito penal destina-se a punir fatos causadores de lesões efetivas ou de ameaças concretas e diretas a direitos, postos em efetivo perigo de perecimento. Há de se considerar a pena como conseqüência da prática de crime, conceituação juridicamente lógica e antecedente à tarefa de cominar penas.

A solução mais adequada para impor-se sanção penal, como resposta a ações delituosas, é a que parta de uma definição jurídica de ilícito criminal. $O$ crime, segundo uma linha sistemática, deveria ser definido como categoria contrária ao direito, pelo ramo próprio, isto é pelo direito criminal, único detentor das condições de amplo domínio doutrinário, necessárias para fixar conceitos substanciais sobre condutas contidas nos preceitos das normas incriminadoras. Somente após a definição das condutas que constituem crime é que cabe a previsão da pena, como resposta que é à prática de condutas delituosas.

Ao contrário do que atualmente acontece no criticável direito penal promocional do Estado, mais preocupado com soluções formais e midiáticas, a ordem jurídica deverá abandonar propostas de penas simbólicas para, prioritária e antecedentemente, identificar as 
condutas verdadeiramente ofensivas aos bens jurídicos fundamentais, segundo o princípio de razoabilidade, adequando as penas ao critério da necessidade de punir.

Sempre que se ultrapassar o limite da necessidade da punição, estabelecido no art. 59 do Código Penal como seu verdadeiro apoio ideológico, quer criando normas incriminadoras desnecessárias, quer impondo condenações desnecessárias ou ultrapassando o limite da necessidade da pena aplicada, estaremos praticando o mais prejudicial atentado contra a verdadeira natureza do direito criminal.

Em conclusão, cabe resumir:

$\mathrm{O}$ disposto do art. $5^{\circ}, \mathrm{XXXV}$, da Constituição Federal, indica como juridicamente relevante a causação de lesões efetivas ou ameças a direitos, só podendo ser entendidas como verdadeiras ameaças as que sejam concretas, pois ameças abstratas inexistem.

Em conseqüência, a ordem jurídica não deve admitir crimes de perigo abstrato, por não conterem as condições concretas e diretas e afetarem bens fundamentais juridicamente protegidos.

A lógica jurídica indica ser prioritária a tarefa de definir o que seja crime, como conduta pelo menos causadora de lesão ou ameaçadora a direito, de modo concreto e direto. Somente após assentada a definição do crime, se fará a previsão da sanção aplicável ao agente; não como acontece quando o legislador parte do interesse de aplicar penas de efeito simbólico, promocional do Estado e de seu interesse em estabelecer a ordem pública, para só depois definir se o fato é substancialmente delituoso por afetar bens essenciais à sociedade.

É inaceitável a inversão ilógica nascida com o direito penal máximo. Ou seja, o ponto de partida na formulação das normas incriminadoras deve ser o reconhecimento da criminalidade da conduta, no preceito do tipo penal, para somente depois se estabelecer a cominação da pena. Do mesmo modo, o juiz somente aplicará pena, segundo o critério da necessidade, se reconhecer a criminalidade substancial de uma conduta. 
